\title{
Cerebral air embolism during upper endoscopy
}

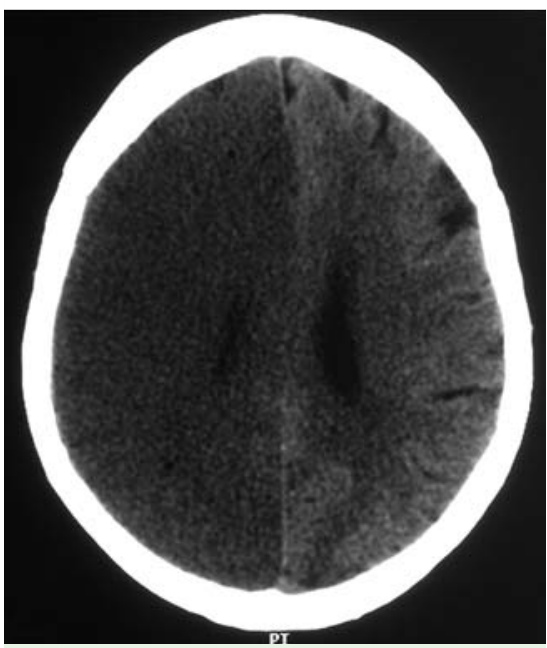

Fig. 1-3 Computed tomography scan of the brain 1 hour after the cerebral event. Numerous small hypodensities consistent with air are displayed in the whole hemisphere.

A 61-year-old woman was admitted due to an episode of hematemesis. Esophagogastroduodenoscopy (EGD) was performed and esophageal varices were described with signs of recent bleeding, for which bands were placed. After the procedure the patient became unresponsive (Glasgow Coma Scale =3/15) and hypotensive (mean arterial pressure $=40$ ), and thus required intubation and ventilation in the intensive care unit. Neurologic signs such as ocular bobbing were noted. Cerebral computer tomography (CCT) revealed pneumocephalus and ischemic infarction of the right hemisphere ( Figs. 1-3). The patient became brain dead within 24 hours of admission.

Air embolism is described as a complication during surgery and invasive diagnostic procedures [1]. There are only 19 cases reported in the literature during EGD, eight of which were cerebral air embolism [2].

Air embolism occurs when there is a communication between the vasculature and an air source, whereby air is forced into the blood down a concentration gradient [3]. The presence of hypotension suggests that air may have passed from the pulmo-

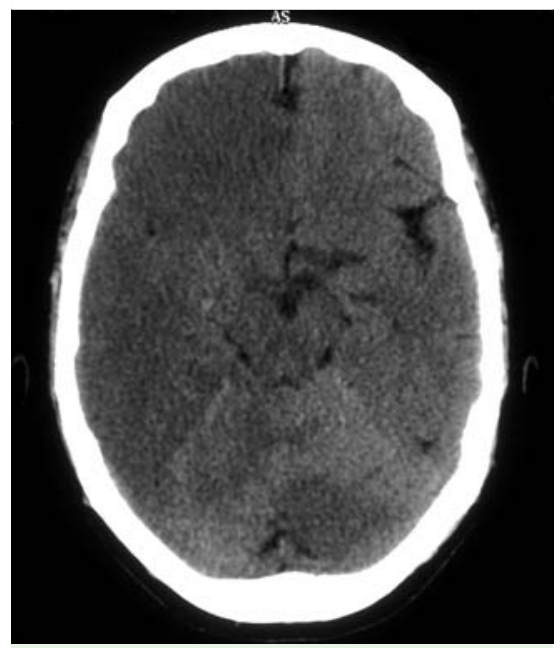

Fig. 2

nary veins to the systemic vasculature via prepulmonary arteriovenous shunts or directly via the pulmonary capillary bed. Air embolism may produce ischemia of any organ with limited collateral circulation, and micro-embolization to the cerebral vasculature may produce severe neurologic damage [4].

CCT is highly sensitive for air embolism but is only diagnostic if performed immediately, as air is rapidly reabsorbed from cerebral arterioles. In addition, cardiac shunt is not always detectable by echocardiography or chest CT [2].

Treatment involves prevention of further embolization, high-flow oxygen, hyperbaric therapy, left-lateral decubitus or Trendelenburg's position, and aspiration of air from the right ventricle using a central venous catheter.

Prognosis depends upon the clinical setting and the volume of the air embolism. Mortality rate for untreated patients is greater than 90\%; however hyperbaric therapy can reduce it to $7 \%$; though the majority of survivors will present neurologic deficits [5]. Cerebral air embolism is usually catastrophic, but its sequelae can be greatly improved by prompt CCT and treatment with hyperbaric therapy.

Endoscopy_UCTN_Code_CPL_1AH_2AB

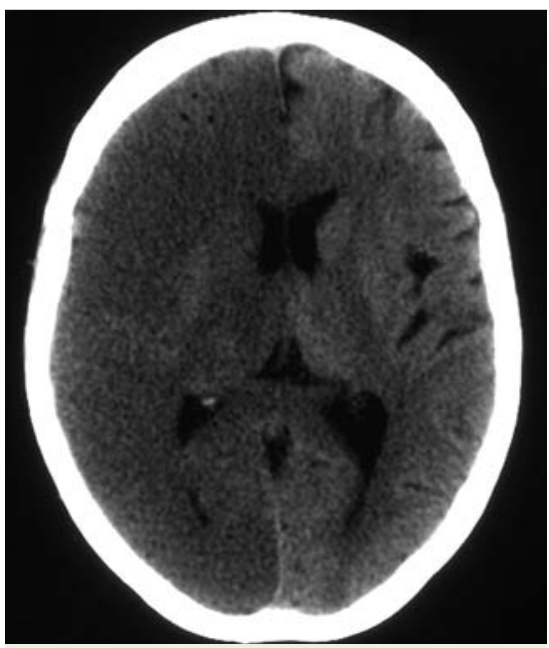

Fig. 3

\section{J. C. López, X. Pérez, F. Esteve}

Department of Intensive Care, Hospital Universitari de Bellvitge, Hospitalet de Llobregat, Barcelona, Spain

\section{References}

1 Green BT, Tendler DA. Cerebral air embolism during upper endoscopy: case report and review. Gastrointest Endosc 2005; 61: 620 623

2 McAree BJ, Gilliland R, Campbell D et al. Cerebral air embolism complicating EGD. Endoscopy 2008; 40: E191 -E192

3 Herron DM, Vernon JK, Gryska PV, Reines HD. Venous gas embolism during endoscopy. Surg Endosc 1999; 13: 276 - 279

4 Lowdon JD, Tidmore TL. Fatal air embolism after gastrointestinal endoscopy. Anesthesiology 1988; 69: 622-623

5 Dunbar EM, Fox R, Watson B, Akrill P. Successful late treatment of venous air embolism with hyperbaric oxygen. Postgrad Med J 1990; 66: 469-470

Bibliography

DOI $10.1055 / \mathrm{s}-0029-1215313$

Endoscopy 2010; 42: E41

(c) Georg Thieme Verlag KG Stuttgart · New York . ISSN 0013-726X

\section{Corresponding author \\ J. C. López, MD}

Department of Intesive Care

Hospital Universitari de Bellvitge

C/ Feixa Llarga s/n. Hospitalet de Llobregat Barcelona

Spain

Fax: +34-93-3319412

Juancarloslopezde@hotmail.com 